\title{
Internet Transaction Anxiety \& Recognition of Assurance Services
}

\author{
Clinton E. White, Jr. \\ University of Delaware. USA. \\ Skipw@udel.edu
}

\begin{abstract}
Many recent surveys and articles have shown that consumers have "Internet transaction anxiety." This study explores specific transaction anxieties related to the services provided by several prominent e-commerce assurance services. Results indicate that consumers are most concerned about their personal information both as it is being transmitted over the Internet and when it is being handled remotely by an e-commerce vendor. However, there is no significant relationship between having major reservations about purchasing via the Internet and actually doing so. Also, the majority of subjects in this study did not recognize assurance service seals designed to alleviate transaction anxieties. A personal safe shopping guarantee from a reputable e-commerce vendor (e.g. Amazon.com) appears to be as effective at alleviating consumer anxiety as a Web assurance seal from an assurance service.
\end{abstract}

Key words: E-commerce, the Internet, Web assurance services.

The author wishes to extend thanks to: Guido Geerts, Thomas Hofferd, and Mark Serva for review and comments of previous drafts of this paper. Also, thanks to Greta Coles (student researcher) for assistance in conducting the research.

Data is available upon request.

\section{INTRODUCTION}

Many recent surveys conclude that consumers are concerned about providing personal and financial information, especially credit card numbers, to merchants to purchase items by way of the Internet; referred to hereafter as Internet transaction anxiety. Typical is the National Technology Readiness Survey (1999) of 1,001 households over a two-year period, conducted by Rockbridge Associates, which reached the following conclusions: 
- $58 \%$ do not consider any online financial transaction to be safe.

- $67 \%$ do not have confidence in a company that can only be reached online.

- $77 \%$ do not think providing a credit card number online is safe.

- $87 \%$ want e-commerce transactions confirmed in writing (Beale 1999).

Internet transaction anxiety is not without foundation. ICSA.net (1999) conducted a study of 54 corporate e-business sites that had implemented traditional security technologies and policies to mitigate risk. The study showed that:

- $60 \%$ were subject to denial of service attacks.

- $80 \%$ did not know what services were on their network and visible over the Internet.

- $80 \%$ had insufficient security policies.

- $70 \%$ of sites with firewalls remained vulnerable to known attacks. (ICSA.net 1999)

More recently, the Center for Education and Research in Assurance and Security (2001) released a study concluding that security risks are at an historic high because of such factors as the following:

- Sharing information through virtual business relationships and the complexities of securing massive amounts of personal data.

- The necessity to trust electronic systems to recognize what is authorized and what is unauthorized access.

- Network security systems that are being "... stretched to the limit by an everexpanding digital economy.” (Micek 2001)

The year 2000 saw a number of Internet security related incidents and the involvement of the U.S. Federal Bureau of Investigation, the U.S. Federal Trade Commission (FTC), and the European Union. Early in the year, DoubleClick, an on-line advertising company, was sued for unlawfully obtaining and selling personal and financial information. Following a complaint filed by the Electronic Privacy Information Center, the FTC launched a formal investigation into its methods of gathering and using consumer information (Brady 2000). In February, the FTC released a report based on a study by the California HealthCare Foundation which concluded " ... that most health-related Web sites were not honoring their promises to keep personal information about visitors private" (Clausing 2000). In July the FTC intervened when Toysmart.com attempted to sell its consumer data to a third 
party (Richtel 2000) and in August Toysrus.com was hit with a class action law suit for disclosing personal consumer data to third parties from 1998 to the present (Enos 2000).

All interested parties, including consumers, e-businesses, and governmental agencies, are concerned about consumer privacy and the security of Internet-based commerce transactions. In terms of world-wide legislation and regulatory proposals, the Organization for Economic Cooperation and Development (a Paris-based policy group with representatives from 29 nations) and The Electronic Commerce and Consumer Protection Group (composed of 7 of the world's leading Internet and ecommerce companies) have proposed guidelines designed to inform and protect online consumers (Enos and Greenberg 2000). The U.S has indicated it will endorse the completed version of the European Cybercrime Proposal, which is designed to remove or minimize procedural and jurisdictional obstacles that could delay or endanger international investigations (Weisman 2000). The FTC has now implemented the Children's Online Privacy Protection Act (April 21, 2000) requiring Websites to obtain parental consent before collecting information from children under 13. One result is that virtually all (legitimate) e-business Websites now disclose consumer data collection and security policies and the vast majority carry some form of security or assurance service seal or a personal guarantee.

The need for e-commerce assurance services was recognized early on by accounting professionals and early accounting academic research was primarily directed toward the market for such services and the potential opportunities for CPAs. A study conducted by Gray and Debreceny (1998) addressed assurance services from the perspective of e-businesses and identified potential market niches for such services. Gray and Debreceny concluded that CPAs "are in an excellent position to provide assurance to consumers" (p. 33) concerning e-commerce but that the market for these services is competitive and most clients may not be ready for such services. A separate study (Greenstein 1998) investigated the evolving role of the accounting profession in providing Internet assurance services. The author concluded that public perception of the credibility and worth of these services is a current issue that needs to be further investigated (Greenstein 1998). More recently, accounting researchers have found evidence that the CPA WebTrust seal in particular promotes "higher online transaction expectations and stronger intent to purchase" (Kovar, et. al. 2000). Consumer advocacy groups have been more skeptical. Mark Rotenberg of the Electronic Privacy Information Center states that the seals "are just a colorful link to a privacy policy that can say almost anything" (Guernsey 1999) and also "we are witnessing the slow erosion of online privacy under the industry's self-regulatory approach" (Regan and Saliba 2000). 


\section{E-COMMERCE ASSURANCE SERVICES}

Internet-based businesses are taking proactive measures to allay consumers' anxieties about purchasing merchandise and services over the Internet. Most hire the services of one or more Web assurance certifying services, undergo a review of procedures, make any necessary adjustments to meet the criteria for certification, and display seals that indicate compliance. Today there are a number of seals and security guarantees from which to choose, each with its own unique focus, meaning, and approach to Internet security. This research project focused on five wellrecognized services and a personal safe shopping guarantee:

1) VeriSign - A digital certificate program focused on the encryption of data sent from and received by Web servers.

2) CPAWebTrust - A certification program developed by the American Institute of CPAs.

3) TRUSTe - A non-profit organization developed in concert with CPAs.

4) BBBOnLine - The Better Business Bureau Online security seal which requires a company to be a member in good standing of the BBB organization.

5) TruSecure - A certification program developed by the International Computer Security Association that focuses on network security.

6) Amazon.com - A personal guarantee from one of the best known Internetbased e-commerce companies.

\subsection{VeriSign}

VeriSign specializes in digital authentication certificates for Web servers. VeriSign is the leading representative of what are known as Internet "certificate authorities." To receive a VeriSign digital certificate, an e-commerce business applies for a class 3 authentication certificate for each of its Web servers, proves its identity by providing a verifiable domain name server address, and pays a yearly fee. The cost of a VeriSign certificate varies depending on the level of encryption security desired (40-bit or 128-bit encryption), performance and security analysis services, and insurance coverage. A digital certificate identifies a Web site uniquely and binds that identity to a pair of encryption keys that allow the site to send and receive encrypted, digitally signed information. Referred to as a "secure server," a user's Web browser automatically recognizes the server's certificate and saves its identifying characteristics including the identity of the issuing certificate authority. The certificate assures a consumer of the identity of an e- 
commerce Web site and that the personal information keyed into a form to purchase an item or a service will be encrypted and cannot be read or changed during transmission to the e-commerce server.

Authentication and encryption are the most fundamental levels of assurance that consumers should demand from an e-commerce site. By default, a browser notifies a user when providing personal information on secure pages and allows the user to easily check the identity of an e-commerce site. In addition, VeriSign boasts that their "authentication procedures have withstood the most rigorous scrutiny from independent third-party auditors" and that they are "the only Certificate Authority in the world to have passed an extensive independent Type \#SAS 70 audit by KPMG" (Verisign 2000). They now service over 400,000 Web sites (www.verisign.com).

\subsection{CPA WebTrust}

The CPA WebTrust program was launched jointly by the American Institute of CPAs (AICPA) and the Canadian Institute of Chartered Accountants (CICA) in September, 1997. It was developed to meet two critical needs in the expanding online marketplace - consistent standards and consumer trust (AICPA 2001). To qualify for a CPA WebTrust seal, an e-commerce business must receive an unqualified report from a properly trained auditor and agree to be re-certified at least every 90 days. The standards that a Web-based business-to-consumer Web site must meet are as follows:

- Disclose business and information privacy practices for e-commerce transactions and execute all transactions accordingly.

- Maintain effective controls to provide reasonable assurance that customers' transactions using e-commerce are completed and billed as agreed.

- Maintain effective controls to provide reasonable assurance that private customer information obtained as a result of e-commerce is protected from uses not related to business activities. (AICPA 2001)

The cost of a CPA WebTrust assurance starts at about $\$ 8,000$ and can cost much more depending on the size of the e-business, the amount of e-commerce traffic, and the size of the CPA firm. In addition to meeting the WebTrust standards, the e-business must also maintain a VeriSign certificate. As of January 2001 there are twenty-four sites listed in the official CPA WebTrust index (AICPA 2001). From the perspective of an e-commerce business, the CPA WebTrust program is quite similar to an audit. An e-businesses' management makes assertions about 
the three standards described above and a certified auditor collects evidence and issues an opinion as to the reliability of those assertions. To remain current, the audit must be redone regularly every 90 days. From this point of view, the CPA WebTrust certification represents an on-going relationship with an auditor. The obvious difference from a financial statement audit is that it is voluntary.

\subsection{Trust-e}

TRUSTe, a non-profit organization devoted to the disclosure of privacy policies and the appropriate use of private consumer information, was launched in mid 1997 out of Silicon Valley, shortly before the CPA WebTrust program. TRUSTe now "operates as part privacy seal program and part services and consulting by emphasizing industry education guiding prospective licensees on appropriate and legal data gathering and dissemination practices." (Steer 1999). This program has targeted the most highly trafficked e-commerce sites, including AOL, e-Bay, and Yahoo!. To qualify for a TRUSTe seal, an e-commerce Web site must create a privacy statement that meets the TRUSTe principles, pass an initial review by a TRUSTe representative, allow the seeding of information to test the actual implementation of the privacy policies, and agree to periodic monitoring. An appropriate TRUSTe privacy statement must disclose at a minimum the following:

- What personal information is being gathered and by whom.

- How it will be used and with whom it will be shared.

- The choices a consumer has regarding collection, use and distribution of information, including the opportunity to opt-out of secondary usage.

- The security procedures in place, including the use of accepted encryption techniques.

- How users can update or correct inaccuracies in their information. (TRUSTe 2001)

The cost of becoming a TRUSTe site is based on a company's annual revenue - ranging from $\$ 299$ annually for revenue up to $\$ 1$ million to $\$ 6,999$ annually for revenue over $\$ 7.5$ million (TRUSTe 2001). As a non profit organization, TRUSTe uses the fees to offset administrative, oversight, monitoring, and alternative dispute resolution costs. As measured by the number of certified e-commerce sites, over 1,300 including all of the major "portal" sites and 15 of the top 20 most frequented sites, the TRUSTe program is extremely successful. It is estimated that "approximately $90 \%$ of the U.S. Web community is impacted by the TRUSTe privacy seal each month" (Steer 1999). 


\subsection{BBBOnLine}

The BBBOnLine Privacy Program was launched in March 1999 by the Council of Better Business Bureaus. It is an international, voluntary self-regulatory program designed to help reliable, trustworthy businesses identify themselves and users to find them online (CBBB 2001). The BBBOnLine program is based on the premise that "personal information, such as your name, postal and e-mail address or telephone number, is private and confidential," stored securely, accessed only by designated persons, and used only for the purposes intended (CBBB 2001). To be eligible, a company must have a satisfactory record with the Better Business Bureau and must be able to demonstrate the implementation of an acceptable privacy policy and data security measures. The privacy policy must be prominently posted and disclose clearly the following information:

- What information is being collected, its intended usage including sharing, accuracy assurances, and a commitment to its security.

- Contact and process information for follow up, correction, and further investigation, including an authentication mechanism.

- Information about partners and corporate affiliates who might also be collecting information.

- The individual choices available concerning information provision and usage. (CBBB 2001)

In addition, members must provide individuals with the ability to "opt-out" of having their information transferred to third party marketers or used for any other additional purposes.

The cost of becoming a member of BBBOnLine is based on a company's total sales - ranging from an annual fee of $\$ 150$ for sales up to $\$ 1$ million to $\$ 3,000$ for sales over $\$ 2$ billion. The membership fee goes to cover the cost of an annual assessment evaluation of a company's e-commerce site. BBBOnLine claims that 10,000 Web sites carry one or both of their seals (CBBB 2001).

\subsection{TruSecure}

TruSecure is a security certification program designed by the International Computer Security Association (ICSA). ICSA Labs is a for-profit organization that tests and certifies commercial security products. The TruSecure business certification program is a comprehensive partnership designed to plan, evaluate, and test security policies, procedures, software, and hardware. This involves 
TruSecure analysts working with an entity's security staff to accomplish a series of reviews, including the following:

- Security policies, operational policies, and access permissions for critical devices such as firewalls, VPNs (Virtual Private Networks), Web servers, and e-mail servers.

- Anti-virus verification procedures and protection policies and procedures.

- Human resource policies.

- Modem activity testing.

- Remote access policies and procedures.

- Internal file and print server sharing policies.

- Overall security posture and policy assessment. (ICSA.net 1999)

A TruSecure certification is awarded after a company implements the ICSA recommended policies, procedures, and controls. When certified, a company becomes a member of the ICSA.net and is subject to recurring electronic testing and verification and has access to ICSA maintained security information and research. Essentially, the TruSecure program involves a comprehensive security review of an entity's computing networks that focuses on "attainable security, leveraging existing investments and providing a sound, practical framework to follow." (ICSA.net 1999) ICSA has brought together a number of ISPs and telecommunications companies to form a group known as the Alliance for Internet Security. (ICSA.net 1999) The explicit objective of this consortium is improving Internet security technologies and practices in order to prevent future Internetbased e-commerce interruptions such as caused by the rash of successful denialof-service attacks in February, 2000 (Savage 2000). As of January 2001, such attacks are being referred to as currently impossible to stop (Weisman 2001).

The cost of a TruSecure review and certification starts at approximately $\$ 40,000$ and increases in proportion to the complexity of the entity's information systems environment. ICSA claims over 400 companies worldwide (ICSA.net 1999).

\subsection{Amazon.com}

Amazon.com, arguably one of the best-known e-commerce sites in the world, does not display an assurance service seal. Instead, they have an Amazon.com safe shopping guarantee, which states: "We guarantee that every transaction you make at Amazon.com will be safe. This means that you pay nothing if unauthorized charges made to your credit card are a result of shopping at Amazon.com" (Amazon.com 2001). Amazon.com also makes available a privacy notice explaining 
what information is collected about customers, with whom it is shared, how you can access your account and personal information, and that it does not sell to children (Amazon.com 2001). Amazon.com also carries a VeriSign secure server certificate and encrypts all transaction information for transmission across the Internet; it does not however display the VeriSign seal.

It is not known how many e-commerce sites utilize personal safe shopping or privacy guarantees as opposed to displaying assurance service seals. However, Dell.com is another well-known example of this practice. Dell.com prominently displays links to its online privacy practices and a policy statement from Michael Dell (Dell.com 2001) but does not display an assurance service seal. Dell.com does carry a VeriSign certificate and is a member of the BBBOnLine program, but customers will only discover this fact if they drill down into the privacy statements (Dell.com 2001).

\section{THE RESEARCH}

Previous research already sited indicates that there is considerable consumer anxiety about Internet-based e-commerce security, the privacy of personal information, and e-businesses are devoting significant resources to alleviate them. To better understand the relationship between consumer anxieties, consumer knowledge of Internet assurance services, and recognition of the associated seals, the author conducted a survey of senior and graduate accounting students at a major U.S. mid-Atlantic university. College students are heavy Internet users and senior and graduate accounting majors in particular should be familiar with security issues and assurance concerns. The subjects were given a survey (see Appendix A) consisting of three parts. First, a qualifying section with several general questions about purchasing by way of the Internet. Second, ten questions designed to draw out attitudes concerning various risks that assurance services address. Third, a section in which subjects were asked to identify the most recognizable assurance service seals and answer general questions about their meaning. Subjects were considered qualified if they indicated that they would consider making purchases by way of the Internet, regardless of whether they had already done so.

Those qualified were asked to continue. Each participant was asked to consider the following situation before proceeding with the questions:

"You are browsing the Internet and you come across a site that offers books for sale. The site offers a discount for doing business over the Internet and it provides you with the ability to search for your favorite authors and titles, read reviews, and then place an order. The site requests that you provide your name, address, and credit card information for your order to be processed." 
Participants were then asked to answer the remaining questions, all of which started with the phrase "I would ONLY make a purchase if." All questions were designed to elicit attitudes (anxieties) about purchasing by way of the Internet and relevant assurances that they might consider important. All responses were collected using a 5-point Likert scale ranging from "Strongly agree" to "Strongly disagree." These questions were followed by images of the seals of the previously discussed 5 assurance services and the Amazon.com safe shopping guarantee and general questions related to their meaning. Two major objectives of this research methodology were first, to determine the level of concern of the subjects about potential transaction anxieties being addressed by the various assurance services and second, to determine if they recognize major assurance service seals and understand generally what they stand for.

\subsection{Results}

The specific research questions addressed in this project include the following:

- Do Web consumers consider relevant the transaction anxiety factors that prevalent Web assurance services are designed to address?

- Do Web consumers recognize and generally understand the meaning of assurance seals that represent compliance with Web assurance services standards?

The sample of Internet users consisted of 86 senior and graduate accounting majors in classes during the Spring and Fall 2000 semesters. All subjects answered three demographic questions regarding the following: 1) Whether or not they had made a purchase by way of the Internet; 2) Whether or not they had major reservations about doing so; and 3) Whether or not they would consider making such a purchase. Seventy-three percent of the students (63 individuals) reported that they had made a purchase by way of the Internet, leaving 23 who had not. Somewhat surprisingly, 77\% (66 individuals) reported that they do not have major reservations about making a purchase by way of the Internet, leaving only 20 who do (see Table 1). In combination, 65\% (13) of those students who have major reservations have made purchases by way of the Internet anyway (see Table 2). There was no significant correlation between these two factors. Contrary to the previously sited research, the majority of subjects in this study did not have major reservations about making purchases by way of the Internet and having reservations was not a major inhibitor to making such purchases. 


$\begin{array}{lll} & \text { Yes } & \text { No } \\ \text { Have made a purchase: } & 63(73 \%) & 23(27 \%) \\ \text { Have major reservations: } & 20(23 \%) & 66(77 \%) \\ \begin{array}{c}\text { Consider making a purchase: } \\ \multicolumn{2}{c}{\text { Table 1. Prequalification questions }}\end{array} & 86(100 \%) & \end{array}$

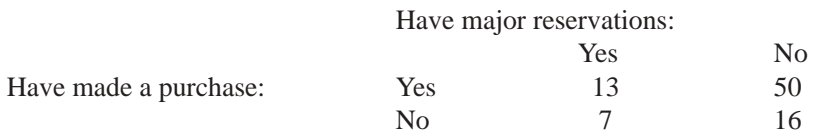

(No significant correlation was identified)

Table 2. Major reservations vs. Have made a purchase

As discussed earlier, each Internet assurance service has its own focus and criteria that an e-commerce site must meet in order to be certified to carry their particular assurance seal. The majority of these criteria address risks of doing ecommerce and represent transaction anxieties that may affect potential consumers. To answer the first research question of whether consumers consider relevant some of the various transaction anxiety factors that Web assurance services are designed to address, the subjects answered 10 questions. The first three questions relate to having confidence in an Internet book vendor based on experience with a "bricks and mortar" outlet, personal reference, and public media. The majority of the remainder of the questions relate in a direct way to one or more criteria of a major Web assurance seal provider (see Table 3). For example, question 4 states that the e-commerce site displays a seal indicating that it encrypts the data being sent; which relates directly to the focus of the VeriSign assurance service. Similarly, question 6 states that the site displays a seal indicating that it has been audited by a CPA; which relates directly to the focus of the AICPA's WebTrust assurance service. In addition to assurance service-related questions, questions 7 and 10 relate to personal money back guarantees and promises to respond quickly to complaints as used by several very popular sites including Amazon.com and Dell.com.

Overall, the subjects indicated the most agreement with questions 4 and 8 . Question 4 states that the subject would make a purchase only if the site displays a seal indicating that it encrypts the data being sent (e.g. the VeriSign assurance service). The mean response for this transaction anxiety item was 2.02 (see Table 3 ), with $77.9 \%$ of the subjects responding in the Strongly agree ... Agree range on the Likert scale. Question 8 states that the subject would make a purchase only if the site displays a seal indicating that personal data will only be used for the purposes of this transaction (e.g. the Trust-e assurance service). The mean response for this transaction anxiety item was 2.05 , with $74.4 \%$ of the subjects responding in the 
Strongly agree ... Agree range. An interesting finding here is that the students are most anxious about the security of their personal information both as it is being transmitted over the Internet and when it is being handled remotely by an ecommerce vendor. It is also interesting to note that the VeriSign and Trust-e assurance services have more major e-commerce vendors as customers than any of the other services.

\begin{tabular}{lrrcrc} 
Question \# & Overall & \multicolumn{2}{c}{ Have made a purchase: } & \multicolumn{2}{c}{ Have major reservations: } \\
(relationship): & mean: & Yes: & No: & Yes: & No: \\
1 (bricks \& mortar) & 3.44 & 3.45 & 3.11 & 3.14 & 3.42 \\
2 (personal ref.) & 2.47 & 2.55 & $2.09^{*} .048$ & 2.23 & 2.41 \\
3 (media) & 2.47 & 2.33 & 2.65 & 2.39 & 2.59 \\
4 (VeriSign) & 2.02 & 2.04 & 1.95 & 1.98 & 2.00 \\
5 (BBB) & 2.65 & 2.76 & $2.13^{*} .003$ & 2.35 & 2.54 \\
6 (WebTrust & 2.91 & 2.97 & $2.35^{*} .006$ & 2.45 & 2.87 \\
7 (Personal guarantee) & 2.23 & 2.26 & 2.23 & 2.29 & 2.20 \\
8 (Trust-e) & 2.05 & 2.00 & 2.16 & 2.07 & 2.10 \\
9 (TruSecure) & 2.26 & 2.09 & 2.30 & 1.98 & $2.41^{*} .037$ \\
10 (Rapid response & 2.70 & 2.59 & 2.50 & 2.28 & $2.81^{*} .021$ \\
to complaints) & & & & &
\end{tabular}

(Notes: 1. Mean responses on a 5-point Likert scale; 2. * indicates a significant difference (LSMeans T-test) between subjects answering $\mathrm{Y}$ and $\mathrm{N}$ on the independent variables: $\mathrm{P}<.05$ )

Table 3. Anxieties about purchasing via the Internet

In addition, the subjects indicated strong agreement with questions 7 and 9 . Question 7 states that the subject would make a purchase only if the site guarantees $100 \%$ satisfaction or your money back (e.g. the personal guarantee from the CEO of Amazon.com). The mean response for this item was 2.23, with $64 \%$ of the subjects responding in the Strongly agree ... Agree range. An interesting finding here, though not surprising, is that the students are anxious about satisfaction and money back guarantees for Internet purchases. Question 9 states that the subject would make a purchase only if the site displays a seal indicating that its networks are tested and certified as secure on a regular basis (e.g. the TruSecure assurance service). The mean response for this item was 2.23 , with $66 \%$ of the subjects responding in the Strongly agree ... Agree range. This finding is also not surprising given the importance that students assigned to questions 4 and 8 , as reported in the previous paragraph.

Subject responses on each of the 10 questions were analyzed further using the GLM procedure (SAS Institute) with 2 independent variables: 1) whether or not they had made a purchase by way of the Internet; and 2) whether or not they have major reservations about doing so (see Table 3). Several significant differences were identified. Those subjects who had not made purchases by way of the Internet, reported significantly $(\mathrm{P}<.05)$ more agreement on three items: Question 2, which 
relates to having confidence in a Web site based on personal references; Question 5 , which relates to the Web site displaying a seal indicating it is part of the Better Business Bureau; and Question 6, which relates to the Web site displaying a seal indicating it has been audited by a CPA. In each case, the responses indicate that those who have not made Internet purchases place significantly more value in these anxiety-related items than those who have (note that lower scores indicate stronger agreement with a question). In addition, those subjects with major reservations about Internet purchases reported significantly more agreement on two items: Question 9, which relates to the Web site displaying a seal indicating that its networks are tested and secure; and Question 10, which relates to quick response to complaints. In each case, the responses indicate that those subjects with major reservations about purchasing by way of the Internet place significantly more value in these anxiety-related items than those who do not.

The answer to the first research question - Do Web consumers consider the factors relevant that prevalent Web assurance services are designed to address, is mixed. Using agreement with specific anxiety questions as the measure, these subjects considered important factors addressed by 3 out of the 5 assurance services plus the personal guarantee of $100 \%$ satisfaction or your money back assurance. When ranked in order of mean agreement scores (in parentheses) we have the following:

1) VeriSign (mean agreement score $=2.02$ ) - an indication that the data is encrypted as it is being sent over the Internet.

2) TRUST-e (2.05) - an indication that your personal data will not be used for other purposes.

3) Personal guarantee (2.23) - indicating 100\% satisfaction or your money back.

4) TruSecure (2.26) - an indication that the e-commerce site's networks are tested and secure.

The subjects were close to neutral about the relevance of e-commerce sites that have an indication that they are part of the Better Business Bureau or an indication that they have been audited by a CPA. However, when analyzed for differences between those who have made a purchase and those who have not, significant differences $(\mathrm{P}<.05)$ were detected indicating that for those who have not made an Internet purchase (23 individuals), personal references, being a member of the Better Business Bureau, and the site being audited by a CPA were more important (see Table 3). Also, when analyzed for differences between those who have major reservations about purchasing over the Internet and those who do not, 
significant differences were detected indicating that for those with major reservations (20 individuals), having the site's networks tested and certified and responding quickly to complaints were more important (see Table 3). Though the samples are small, these data suggest that there are significant differences between the transaction anxieties expressed by those with and without Internet purchasing experience and differences in the level of transaction anxiety among consumers.

The second research question is: Do Web consumers recognize assurance seals and understand the general requirements that an e-commerce site must meet in order to display individual assurance seals. To answer this question, the subjects were asked if they recognize specific seals and, if they do, three general questions concerning each: 1) Does the seal give confidence about the security of personal information; 2) Does it indicate that the business has passed rigorous tests; and 3) Does it give enough confidence to make a purchase. Question 1 is designed to determine if subjects have a general understanding of the security of personal information requirements that an e-commerce site must meet in order to carry a specific assurance service's seal. Subjects who recognize the CPA WebTrust and TRUSTe assurance seals and have a general understanding of their associated requirements for securing and handling personal information, should agree with this question. At the same time, those who recognize the Amazon.com personal guarantee, BBBOnLine, TruSecure, and VeriSign seals, which do not have any personal information security requirements, should not agree. Question 2 is similar in that the CPA WebTrust, TRUSTe, and TruSecure assurance services require an e-commerce site to pass a rigorous body of tests, while the Amazon.com, BBBOnLine, and VeriSign do not. Question 3 is designed to determine if the seal provides enough confidence to make a purchase.

\begin{tabular}{lll} 
& \multicolumn{2}{l}{ Do you recognize this seal? } \\
Seal: & $\underline{\text { Yes }}$ & $\underline{\text { No }}$ \\
VeriSign & 14 & 72 \\
BBBOnLine & 11 & 75 \\
CPA WebTrust & 15 & 71 \\
Amazon.com (presonal guarantee) & 28 & 58 \\
Trust-e & 13 & 73 \\
TruSecure & 4 & 82
\end{tabular}

Table 4. The recognition of assurance seals 
The results show that only a small minority of subjects recognize any of the assurance seals (see Table 4). Individually, the most frequently recognized seal was that of Amazon.com - recognized by 28 (32\%) of the 86 subjects, 23 of whom had made purchases on the Internet. Of the other seals, $15(17 \%)$ of the subjects recognized the CPA Web Trust seal, 14 (16\%) the VeriSign seal, 13 (15\%) the Trust-e seal, 11 (12\%) the BBBOnLine seal, and $4(4 \%)$ the TruSecure seal. Not surprisingly, those who had made purchases by way of the Internet more often recognized seals than those who had not. In addition, subjects responded that all seals provided confidence about the security of personal information, even though some have no related requirements. The CPA WebTrust seal received the highest agreement ranking (86\%) and BBBOnLine the lowest (54\%) (see Table 5). Surprisingly, the Amazon.com personal safe shopping guarantee received a $71 \%$ agreement ranking. Correctly, the subjects who recognized the individual seals reported that businesses carrying the TruSecure, CPA WebTrust, and Trust-e seals had passed a rigorous body of security and integrity tests, while those carrying BBBOnLine, Amazon.com, and VeriSign had not. These results are interesting from several points of view. First, even though the subjects in this study are net savvy college students, the majority do not recognize e-commerce assurance seals. Second, though the samples are small, the subjects who do recognize seals report that most assurance seals (with BBBOnLine being the exception), give them a high level of confidence, suggesting that they do not understand personal information security requirements of the various assurance services. Third, the subjects who recognized them correctly understand that e-commerce sites must pass a rigorous body of tests to carry the TruSecure, CPA WebTrust, and TRUSTe assurance seals.

$\begin{array}{lllc}\text { Seal (recognized by): } & \begin{array}{l}\text { Confidence about } \\ \text { personal information: }\end{array} & \begin{array}{l}\text { Has passed } \\ \text { rigorous tests: }\end{array} & \begin{array}{c}\text { Enough confidence } \\ \text { to make a purchase: }\end{array} \\ \text { VeriSign }(\mathrm{n}=14) & 64 \% \text { agree } & 35 \% \text { agree } & 35 \% \text { agree } \\ \text { BBBOnLine }(\mathrm{n}=11) & 54 \% \text { agree } & 45 \% \text { agree } & 54 \% \text { agree } \\ \text { CPA WebTrust }(\mathrm{n}=15 & 86 \% \text { agree } & 73 \% \text { agree } & 66 \% \text { agree } \\ \text { Amazon.com }(\mathrm{n}=28) & 71 \% \text { agree } & 43 \% \text { agree } & 78 \% \text { agree } \\ \text { Trust-e }(\mathrm{n}=13) & 69 \% \text { agree } & 69 \% \text { agree } & 76 \% \text { agree } \\ \text { TruSecure }(\mathrm{n}=4) & 75 \% \text { agree } & 75 \% \text { agree } & 50 \% \text { agree }\end{array}$

Table 5. Seal recognition and agreement with confidence questions

Finally, the data were analyzed to determine if subjects who recognized the various assurance seals reported having significantly different transaction anxieties then those who did not recognize the seals. Responses to transaction anxiety 
questions 4 through 9 were analyzed using the GLM method with one independent variable, whether or not a subject recognized a corresponding assurance seal. The results indicate that for each anxiety-related question, subjects who recognized a seal reported having slightly higher transaction anxiety (e.g. a mean score closer to 1.0), but the differences were not significant at the $\mathrm{P}<.10$ level (see Table 6). Though the samples are small, this suggests that consumers report that they have transaction anxieties but they do not recognize the seals of the assurance services that are designed to alleviate the associated risks.

\begin{tabular}{lccc} 
& $\begin{array}{c}\text { Question \# } \\
\text { Seal: }\end{array}$ & \multicolumn{2}{c}{ Seal recognized: } \\
VeriSign & 4 & $\underline{\text { Yes }}$ & $\underline{\underline{\text { No }}}$ \\
BBBOnLine & 5 & 1.92 & 2.04 \\
CPA WebTrust & 6 & 2.27 & 2.70 \\
Amazon.com & 7 & 2.53 & 3.00 \\
Trust-e & 8 & 2.07 & 2.31 \\
TruSecure & 9 & 1.84 & 2.09 \\
(Note: No significant differences were identified) & 1.75 & 2.29 \\
\multicolumn{2}{r}{ Table 6. Seal recognition vs. Anxiety about purchasing }
\end{tabular}

\section{CONCLUSIONS}

This research investigated whether students as e-commerce consumers consider relevant the transaction anxiety factors that prominent Web assurance services are designed to address and whether they recognize, understand, and have confidence in the associated Web assurance services' seals. The results of this research indicate the following:

- There is no significant relationship between having reservations about purchasing via the Internet and actually doing so.

- The subjects agree that they have specific anxieties about purchasing via the Internet, but the majority do not recognize the seals of the Web assurance services designed to alleviate the risks associated with those anxieties.

- A personal guarantee from a reputable e-commerce site, such as Amazon.com, seems to be as effective in providing confidence as a Web assurance seal.

Before generalizing these findings to consumers as a whole, these results should be interpreted with several limitations in mind. First, only college students were used as subjects representing Web consumers in this research. Though representative of technology savvy Web consumers, college students may not be 
representative of the larger group of potential Web consumers. Second, the small number of subjects involved. Though appropriate for statistical analysis as a whole group, when divided into categories such as whether or not they had purchased via the Internet and whether or not they have major reservations about doing so, small and unequal cell sizes do not contribute favorably to good analysis. Third, the study only addressed purchasing via the Internet not more sophisticated ecommerce activities such as Internet banking or other financial services.

The majority of subjects in this study do not have major reservations about purchasing via the Inter et and the majority had already done so. Thus they represent a group of e-commerce veterans. Such consumers are most concerned about the confidentiality of their personal information as it is being transmitted over the Internet and as it is handled by an e-commerce merchant. This being the case, they considered most important the encryption of data by an e-commerce business and an assurance that their data would be used only for purposes of the intended transaction but they did not recognize the assurance seals designed to alleviate the associated risks. The majority of subjects did not recognize any Web assurance seals. However, by far the most recognized seal was the personal "safe and easy" guarantee of Amazon.com. This result, however, may simply be an artifact of the subject population of students being familiar with Amazon.com. In addition, even though the subjects were accounting majors, the VeriSign, BBBOnLine, CPA WebTrust, and Trust-e seals were recognized by less than 17\% (15) of the subjects, and the TruSecure seal was recognized by only 4 subjects.

Based on these results, e-businesses would be advised to carefully consider the value-added benefit of a Web assurance service prior to spending their resources. Said another way, an assurance service must provide a tangible security benefit, such as, the encryption of data or a tested and secure network, in order to add value. Assurance seals are not widely recognized, especially by those who have not already purchased via the Internet, so simply indicating that an ecommerce business has been certified by an assurance service does not seem to add value to a Web site. E-commerce sites would be well advised to display a link to their privacy and security practices but not necessarily to an assurance service seal. For consumer confidence in e-commerce, encryption of data during transmission over the Internet and the security and integrity of personal information are extremely important factors. Related to these factors is the security and integrity of the computer networks of the e-commerce business itself. Beyond spending resources to establish and maintain these fundamentals of sound e-business practice, a personal safe shopping guarantee may be sufficient to alleviate consumer anxiety.

As concluded by previous research, the market for assurance services is competitive and their credibility and added value is currently not guaranteed. 
Like previous research, the present study focused only on purchasing via the Internet. As consumers and Web-based e-commerce becomes more sophisticated and more services become available, the importance of assurance services may increase. The recognition and relevance of the various assurance services could also be enhanced by a set of mutually agreeable standards or criteria for transaction security and information privacy. Knowledgeable consumers may in the future demand such standards. Future research could be more specific about different types of information being sent over the Internet and could consider consumer anxiety about such other e-commerce activities as Internet banking, financial services, virtual service providers, and virtual communities.

\section{REFERENCES}

AICPA (2001): Overview of the WebTrust 3.0 Progr. http://www.cpawebtrust.org. (January)

Amazon.com (2001): Safe Shopping Guarantee and Privacy Notice. http:// www.amazon.com. (January)

Baker, R.; White, C.E. (1999): "Internet Uses in Accounting Education: Survey Results", Journal of Accounting Education, vol. 17, n. 2/3 (255-266).

Beale, M. (1999): "Survey Reveals Consumer Concern Over E-Commerce Security Issues", E-Commerce Times Online (June 21).

Brady, M. (2000): "DoubleClick CEO Shrinks From Tough Privacy Questions", E-Commerce Times Online (April 25).

CBBB (2001): Promoting Trust and Confidence on the Internet. Council of Better Business Bureaus. http://www.bbbonline.com. (January).

Clausing, J. (2000): "Report Rings Alarm Bells About Privacy On the Internet", New York Times (February 7).

Dell.com (2001): Online Privacy Practices and Policy Statement from Michael Dell. http://www.dell.com (January)

Enos, L. (2000): “Toys 'R' Us Sued for Net Privacy Violations”, E-Commerce Times Online (April 4).

Enos, L.; Greenberg, P. A. (2000): "Industry Heavywieghts Propose E-Commerce Guidelines", E-Commerce Times Online (June 6).

Guernsey, L. (1999): “Web Surfers' Fears Prompt Privacy Seals”, New York Times (April 29).

Gray, G. L.; Debreceny, R. (1998): "The Electronic Frontier: Boldly going where no CPA has gone before? Take a map", Journal of Accountancy (May): 32-38. 
Greenstein, M. (1998): "Web Site Attestation - A study of Licensed Providers", Paper presented at the seventh Annual Research Workshop on Artificial Intelligence and Emerging Technologies in Accounting, Auditing and Tax. (August): 43-55.

ICSA.net. (1999): Information Security: A Practical Solution For Senior Management. ICSA.net Whitepaper (May).

Kovar, S. E.; Burke, K. G.; Kovar, B. R. (2000): "Consumer Responses to the CPA WEBTRUST Assurance”, Journal of Information Systems 14 (1): 17-35.

Micek, J. L. (2001): “Study: Net Security Systems Overwhelmed”, E-Commerce Times Online (January 9).

Regan, K.; Saliba, C. (2000): "Privacy Watchdogs Blast Amazon", E-Commerce Times Online (September 14).

Richtel, M. (2000): "F.T.C. Moves to Halt Sale Of Database at Toysmart", New York Times (July 11).

Savage, M. (2000): "ISPs, Telecoms Form Alliance to Fight Web Attacks", Computer Reseller News Online (February 24).

Steer, D. (1999): "Privacy Practices Help Build Trust, Get and Retain Web Customers", http://Ecnow.com (October 29).

TRUSTe (2001): Model Privacy Statement. http://www.truste.org. (January)

Weisman, R. (2000): "U.S. Endorses European Cybercrime Proposal", ECommerce Times Online (December 5).

Weisman, R. (2001): “DoS Attacks: Internet Plague Without A Cure?”, E-Commerce Times Online (January 31).

\section{APPENDIX}

\subsection{Part 1: Anxiety questions}

Have you ever purchased something by way of the Internet?

Y N

Do you have major reservations about purchasing over the Internet? $\quad \mathrm{Y} \quad \mathrm{N}$

Would you consider making a purchase by way of the Internet? $\quad \mathrm{Y} \quad \mathrm{N}$

*If Yes, please continue.

You are browsing the Internet and you come across a site that offers books for sale. The site offers a discount for doing business over the Internet and it provides you with the ability to search for your favorite authors and titles, read reviews, and then place an order. The site requests that you provide your name, address, and credit card information for your order to be processed. 


\section{I would ONLY make a purchase if:}

1) I had purchased from a regular store under the same name. Strongly Agree Agree Neutral Disagree Strongly Disagree

2) I had confidence in the vendor through personal references.

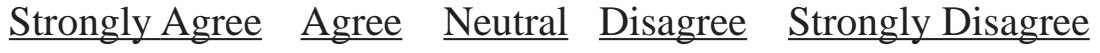

3) I had confidence in the vendor through public media. Strongly Agree Agree Neutral Disagree Strongly Disagree

4) The site displays a seal that indicates that it encrypts the data that you send.

Strongly Agree Agree Neutral Disagree $\underline{\text { Strongly Disagree }}$

5) The site displays a seal indicating that it is part of the Better Business Bureau on-line.

$\underline{\text { Strongly Agree Agree Neutral Disagree }}$ Strongly Disagree

6) The site displays a seal indicating that it has been audited by a CPA.

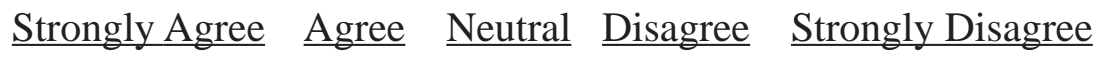

7) The site guarantees $100 \%$ satisfaction or your money back.

$\underline{\text { Strongly Agree Agree Neutral Disagree }}$ Strongly Disagree

8) The site displays a seal that indicates that your personal data will not be used for purposes other than sending the order and related merchandise information.

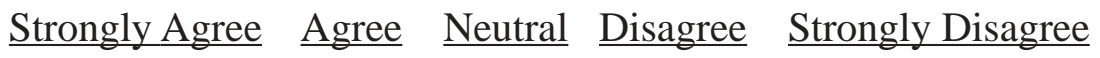

9) The site displays a seal that indicates that its networks are tested and certified as secure on a regular basis.

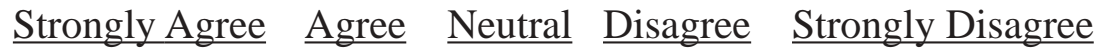

10) The site displays a seal that indicates that the business will respond to customer complaints within seven business days.

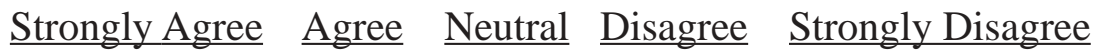




\subsection{Part 2: Assurance seals}

On the next pages you will find several seals that are currently being displayed by companies doing business on the Internet. For each seal that you recognize, please indicate your level of agreement with the associated statements.

1) I do not recognize this seal.

2) This seal gives me a high level of confidence that my personal information will be safe and secure.

$\underline{\text { Strongly Agree }}$ Agree Neutral Disagree Strongly Disagree

3) This seal indicates that the business has passed a rigorous body of security and integrity tests.

Strongly Agree Agree Neutral Disagree Strongly Disagree

4) This seal gives me enough confidence that I would make a purchase via the Internet.

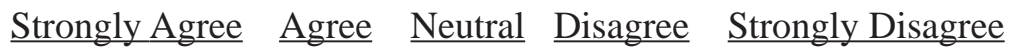
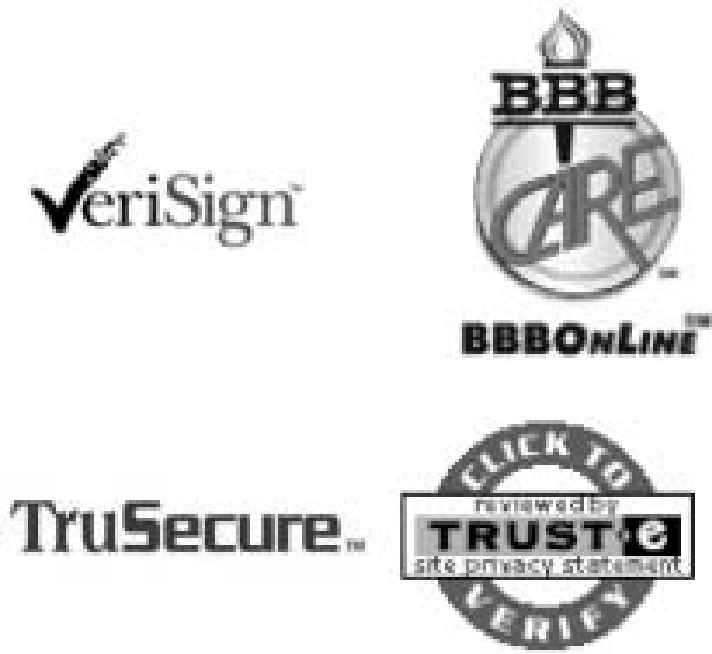

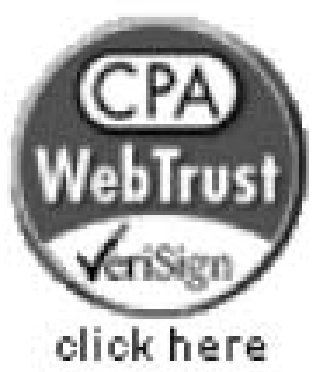

click here 